\title{
Faktor-Faktor Yang Mempengaruhi Beralih Pekerjaan Pada Petani Karet di Desa Tanjung Mancang Kecamatan Kejuruan Muda Kabupaten Aceh Tamiang
}

\author{
Ika Nurniaty ${ }^{1}$, M. Jamil ${ }^{2}$ \\ 1,2 Program Studi Agribisnis Fakultas Pertanian Universitas Samudra \\ *Corresponding author's e-mail: milcareca@gmail.com
}

\begin{abstract}
ABSTRAK
Harga dan produksi karet yang tidak stabil sehingga berpengaruh pada pendapatan petani. Petani dapat melihat kesempatan kerja yang lebih menjanjikan dari usahatani karet sehingga terjadi beralihnya petani ke pekerjaan lain. Penentuan lokasi dilakukan secara purposive yaitu Kecamatan Kejuruan Muda Kabupaten Aceh Tamiang dengan jumlah sampel sebanyak 30 petani. Alat analisis yang digunakan yaitu analisis regresi linier berganda dengan variabel bebas yaitu pendapatan, pendidikan, keterampilan petani dan variabel terikat yaitu kesempatan beralih pekerjaan. Hasil penelitian menunjukkan bahwa variabel pendapatan dan pendidikan berpengaruh terhadap kesempatan beralih pekerjaan, sedangkan variabel keterampilan petani tidak berpengaruh.
\end{abstract}

Kata Kunci:

harga; karet; pendapatan, keterampilan

\section{ABSTRACT}

Rubber price and production was unstable and effected to farmer profit. Farmer looking for another chance which is from their rubber so farmer change their job to others. Location choose with purposive sampling that is Kejuruan Muda Sub-district, Aceh Tamiang district while the sample 30 farmers. The analysed used multiple linear regression with independent variable are profit, education, farmer skill and dependent variabel is opportunity to change jobs. The result showed that profit and education variable effected opportunity to change jobs, meanwhile farmer skill wasn't.

Keyword:

price; rubber; profit; skill

How to cite: Nurianty,I., M. Jamil (2019), Faktor-Faktor Yang Mempengaruhi Beralih Pekerjaan Pada Petani Karet di Desa Tanjung Mancang Kecamatan Kejuruan Muda Kabupaten Aceh Tamiang. Jurnal Penelitian Agrisamudra. 6(1): 48-53

\section{Pendahuluan}

Sektor pertanian terbagi ke dalam beberapa subsektor, salah satunya adalah subsektor perkebunan. Perkebunan merupakan subsektor strategis yang secara ekonomis, ekologis dan sosial budaya memainkan peranan penting dalam pembangunan nasional. Karet alam merupakan salah satu komoditas pertanian yang sangat penting untuk Indonesia dan lingkup Internasional. Di Indonesia, karet merupakan salah satu hasil pertanian yang banyak menunjang perekonomian negara. Hasil devisa yang diperoleh dari karet cukup besar. Bahkan Indonesia pernah menguasai produksi karet dunia dengan mengungguli hasil negara-negara lain dan negara asal tanaman karet sendiri yaitu di daratan Amerika Selatan (Panduan Lengkap Karet, 2012). Perkebunan 
karet rakyat merupakan sumber mata penghasilan bagi keluarga petani karet. Desa Tanjung Mancang merupakan salah satu desa yang terletak di Kecamatan Kejuruan Muda Kabupaten Aceh Tamiang dengan mata pencaharian penduduknya sebagai petani karet. Sebagian penduduk desa tersebut mengandalkan penghasilannya dari bertani karet.

Usahatani karet merupakan suatu kegiatan usaha komoditas karet. Usaha ini diharapkan dapat memberikan kesejahteraan bagi petani karet. Namun pada saat ini untuk mencapai harapan tersebut merupakan hal yang sulit. Hal ini terjadi dikarenakan harga dan produksi karet yang tidak stabil sehingga berpengaruh pada pendapatan petani. Pendapatan yang rendah mendorong petani untuk berusaha mencari pekerjaan lain, dimana pekerjaannya tersebut akan meningkatkan pendapatan. Untuk memperoleh pekerjaan lain, tentu perlu adanya bekal yang dipersiapkan seperti ilmu pengetahuan dan ketrampilan. Dalam hal memperoleh ilmu pengetahuan, tentu perlu menempuh pendidikan yang lebih tinggi. Sedangkan untuk memiliki ketrampilan, perlu mengikuti pelatihan-pelatihan sesuai ketrampilan yang diminati. Pada dasarnya ketrampilan dapat diperoleh secara autodidak atau ketrampilan yang sudah ada pada diri individunya pun dengan cara mengikuti pelatihan-pelatihan. Sebelum menempuh pendidikan yang lebih tinggi dan agar ketrampilan yang dimiliki tidak sia-sia, tentu perlu melihat adanya peluang. Dalam hal ini, petani dapat melihat peluang atau kesempatan kerja yang lebih menjanjikan dari usahatani karet.

\section{Metode Penelitian}

Penelitian ini dilaksanakan di Desa Tanjung Mancang Kecamatan Kejuruan Muda Kabupaten Aceh Tamiang dengan menggunakan metode survei. Penentuan lokasi penelitian dilakukan dengan sengaja (purposive), dengan pertimbangan bahwa lokasi tersebut cocok dengan penelitian yang akan dilakukan dan objek yang dibutuhkan terdapat di daerah tersebut yaitu karet. Ruang lingkup penelitian ini meliputi faktorfaktor yang mempengaruhi beralih pekerjaan pada petani karet seperti pendapatan petani karet, pendidikan dan ketrampilan yang dimiliki petani karet di Desa Tanjung Mancang Kecamatan Kejuruan Muda Kabupaten Aceh Tamiang. Penentuan sampel dilakukan secara simple random sampling (sampel acak sederhana). Metode sampel acak sederhana adalah teknik penentuan sampel secara acak tanpa mengenal sampel dengan cara diundi dengan mengikut sertakan semua populasi yang ada untuk dipilih secara acak. Jumlah sampel yang diambil adalah sebanyak 30 sampel atau berkisar $37,5 \%$ dari populasi. Jumlah populasi petani karet di daerah penelitian sebanyak 80 orang. Sedangkan jumpah petani sampel sebanyak 30 orang, yang terdiri dari 9 orang Dusun Sepakat, 7 orang Dusun Selawi, 3 orang Dusun Paya Batu, 5 orang Dusun Purwosari dan 6 orang Dusun Harapan Jaya.

Untuk menguji hipotesis yang telah dirumuskan maka dianalisis dngan menggunakan regresi linear berganda yaitu analisis regresi yang memiliki satu variabel dependen dan lebih dari satu variabel independen. Variabel penelitian ini terdiri dari tiga variabel bebas dan satu variabel terikat yang persamaanya dapat dirumuskan sebagai berikut :

$Y=a+b_{1} X_{1}+b_{2} X_{2}+b_{3} X_{3}+e$ 


\section{Dimana:}

$$
\begin{aligned}
& \mathrm{Y}=\text { Beralih pekerjaan (Skor) } \\
& \mathrm{X}_{1}=\text { Pendapatan petani karet (Rp/Tahun) } \\
& \mathrm{X}_{2}=\text { Pendidikan petani karet (Tahun) } \\
& \mathrm{X}_{3}=\text { Keterampilan petani (Skor) } \\
& \mathrm{a} \quad \text { Konstanta } \\
& \mathrm{e} \quad=\text { error } \\
& b_{n} \quad=\text { parameter yang dicari }
\end{aligned}
$$

Pengujian Statistika Hasil Regresi

Koefisien Determinasi $\left(\mathrm{R}^{2}\right)$

Koefisien determinasi $\left(\mathrm{R}^{2}\right)$ bertujuan untuk mengetahui seberapa besar kemampuan variabel independen menjelaskan variabel dependen, dengan rumus sebagai berikut:

$$
R^{2}=\frac{J K(\operatorname{Re} g)}{\Sigma Y^{2}} \ldots \ldots \ldots \ldots \ldots \ldots \ldots \ldots
$$

Dimana:

$\mathrm{R}^{2} \quad=$ Koefisien determinasi

JKreg = Jumlah kuadrat regresi

$\sum Y^{2}=$ Jumlah kuadrat total

Uji Signifikan Simultan (Uji Statistik F)

Uji statistik F pada dasarnya menunjukkan apakah semua variabel independen atau bebas yang dimasukkan dalam model mempunyai pengaruh secara bersama-sama terhadap variabel dependen. Pengujian setiap koefisien regresi bersama-sama dikatakan signifikan bila nilai $\mathrm{F}$ hitung $>\mathrm{F}$ tabel maka hipotesis nol (Ho) ditolak dan hipotesis alternatif (Ha) diterima. Uji secara simultan bertujuan untuk mengetahui pengaruh bersama-sama variabel independen terhadap variabel dependen, dengan rumus sebagai berikut:

$$
F_{c a r i}=\frac{J K \operatorname{Reg} / k}{J K \operatorname{Res}(n-k-1)}
$$

Dimana:

JKreg = Jumlah kuadrat-kuadrat untuk regresi

$\mathrm{k}=$ Banyaknya variabel bebas

JKres = Jumlah kuadrat-kuadrat residu

$\mathrm{n} \quad=$ Jumlah sampel

Dengan kriteria pengambilan keputusan:

Jika Fcari > Ftabel maka terima Ha tolak Ho

Jika Fcari $\leq$ Ftabel maka tolak Ha dan terima Ho

Uji Signifikan Parameter Individual (Uji Stastistik t)

Uji secara parsial (uji t) bertujuan untuk mengetahui besarnya masing-masing variabel independen secara individual (parsial) terhadap variabel dependen, dengan rumus sebagai berikut : 


$$
t_{\text {Cari }}=\frac{a_{1}}{S_{a i}}
$$

Dimana:

tcari $=$ Nilai $\mathrm{t}$

$\mathrm{a}_{1} \quad=$ Nilai koefisien regresi ke $\mathrm{k}$

Sai = adalah simpangan baku koefisien $\mathrm{b}$ yang ke $\mathrm{k}$

Dengan kriteria pengambilan keputusan:

Jika tcari $>$ ttabel maka terima Ha dan tolak Ho

Jika tcari $\leq$ ttabel maka tolak Ha dan terima Ho

\section{Hasil dan Pembahasan}

Hasil analisis yang diperoleh yaitu :

$Y=3,110-0,013 X_{1}+0,027 X_{2}+0,146 X_{3}$.

Dari persamaan regresi dapat disimpulkan bahwa :

- Jika pendidikan dan ketrampilan tetap, maka setiap penambahan pendapatan per tahun sebesar Rp. 1.000.000 akan menyebabkan berkurangnya minat beralih pekerjaan pada petani karet sebesar 0,013 skor.

- Jika pendapatan dan ketrampilan tetap, maka setiap penambahan 1 tahun pendidikan akan meningkatkan minat beralih pekerjaan pada petani sebesar 0,027 skor.

- Jika pendapatan dan pendidikan tetap, maka setiap penambahan 1,00 skor ketrampilan maka akan menambah minat beralih pekerjaan pada petani karet sebesar 0,146 skor.

Hasil pengujian menghasilkan nilai $\mathrm{R}^{2}$ sebesar 0,277. Artinya bahwa pengaruh pendapatan, pendidikan dan ketrampilan terhadap beralih pekerjaan pada petani karet di Desa Tanjung Mancang Kecamatan Kejuruan Muda Kabupaten Aceh Tamiang sebesar $27,7 \%$. Sisanya $72,3 \%$ dipengaruhi oleh faktor lain yang tidak dimasukkan dalam model penelitian ini.

Untuk mengetahui besarnya pengaruh pendapatan, pendidikan dan ketrampilan terhadap beralih pekerjaan pada petani karet di Desa Tanjung Mancang Kecamatan Kejuruan Muda Kabupaten Aceh Tamiang secara serempak di uji dengan menggunakan uji F. Hasil pengujian secara serempak (Uji F) sebagaimana disajikan pada tabel berikut ini :

Tabel 1. Uji F

\begin{tabular}{|c|c|c|c|c|c|c|}
\hline \multirow{2}{*}{ No } & \multirow{2}{*}{ Variabel } & \multirow{2}{*}{ Fcari } & \multicolumn{2}{|c|}{$\mathrm{F}_{\text {Tabel }}$} & \multirow[t]{2}{*}{ Keterangan } & \multirow[t]{2}{*}{ Kesimpulan } \\
\hline & & & $a=0,05$ & $a=0,01$ & & \\
\hline 1 & Pendapatan & \multirow{5}{*}{3,318} & \multirow{5}{*}{2,98} & \multirow{5}{*}{4,64} & FCari $>$ & \multirow{5}{*}{$\begin{array}{l}\text { Secara } \\
\text { serempak } \\
\text { berpengaruh } \\
\text { nyata }\end{array}$} \\
\hline 2 & Pendidikan & & & & FTabel & \\
\hline 3 & Keterampila & & & & $\alpha=0,05$ & \\
\hline & $\mathrm{n}$ & & & & FCari $<$ & \\
\hline & & & & & $\begin{array}{l}\text { FTabel } \\
a=0,01\end{array}$ & \\
\hline
\end{tabular}

Sumber : data primer 
Untuk melihat pengaruh secara parsial pengaruh variabel pendapatan, pendidikan dan ketrampilan terhadap beralih pekerjaan pada petani karet di Desa Tanjung Mancang Kecamatan Kejuruan Muda Kabupaten Aceh Tamiang dapat dilihat pada tabel berikut ini :

Tabel 2. Uji t

\begin{tabular}{llcll}
\hline \multicolumn{1}{c}{ Variabel } & Tcari & Sig & Kesimpulan & \multicolumn{1}{c}{ Keterangan } \\
\hline Pendapatan (X1) & $-2,067$ & 0,049 & tSig $<0,05$ & Berpengaruh nyata \\
Pendidikan (X2) & 2,813 & 0,009 & tSig $<0,01$ & $\begin{array}{l}\text { Berpengaruh sangat } \\
\text { nyata }\end{array}$ \\
& & & tSig $>0,05$ & Tidak berpengaruh \\
\hline
\end{tabular}

Sumber : data primer

\section{Kesimpulan}

Secara parsial diperoleh bahwa variabel pendapatan berpengaruh nyata terhadap beralih pekerjaan pada petani karet di Desa Tanjung Mancang Kecamatan Kejuruan Muda Kabupaten Aceh Tamiang dan pendidikan berpengaruh sangat nyata terhadap beralih pekerjaan pada petani karet. Sedangkan variabel ketrampilan tidak berpengaruh terhadap beralih pekerjaan pada petani karet di Desa Tanjung Mancang Kecamatan Kejuruan Muda Kabupaten Aceh Tamiang.

\section{Daftar Pustaka}

Cahyono, B.T. 2016. Masalah Petani Gurem. Liberty. Yogyakarta.

Direktorat Jenderal perkebunan. 2017. Statisti Perkebunan Indonesia 2016 - 2018. Sekeretariat Direktorat Jenderal Perkebunan, Jakarta.

Farhani, Ardianto. 2009. Motivasi Sosial Ekonomi Petani Beralih Pekerjaan dari Sektor Pertanian Ke Sektor Industri Kerajinan Mebel di DesaSeretan Kecamatan Juwiring Kabupaten Klaten. Universitas Surakarta.Surakarta.

Irianto, Agus. 2015. Statistik: Konsep dasar, Aplikasi dan Pengembangannya. Edisi Empat. Prenademedia Group.Jakarta.

Karsidi, Ravik. 2003. Dari Petani Ke Pengrajin : Sebuah Studi Transformasi Pekerjaan. Pustaka Cakra Surakarta. Jakarta.

Khaafidh, M dan Dwisetia P. 2013. Faktor-faktor yang Mempengaruhi Keputusan Tenaga Kerja untuk Bekerja di Kegiatan Pertanian (Studi Kasus : Kabupaten Rembang). Diponegoro Journal Of Economics.. 2(2) : 1-13.

Maslini. 2006. Analisis Jaringan Komunikasi Pada Kelompok Swadaya Masyarakat. Kasus KSM di DesaTaman Sari Kabupaten Bogor, Provinsi Jawa Barat.Tesis. Program PascaSarjana. IPB. Bogor.

Nasir, Z. M. 2005. An Analisys of Accupational Choice in Pakistan, A Multinominal Approach. The Pakistan Development Review, pp. 57-59.

Nazir, M. 2011. Metode Penelitian. Ghalia Indonesia. Bogor.

Putri, Idel. 2014. Pendapatan Petani karet Dalam Meningkatkan Pendidikan Anak Usia Dini Di Desa Sungai Ayak Li Kabupaten Sekadau. Universitas Tanjung Pura. Pontianak. Scott, James C. 1993. Perlawanan Kaum Tani. Yayasan Obor Indonesia. Jakarta.

Siswono, Yodo H. 2004. Pertanian mandiri : Pengantar Strategi Para Pakar Untuk Kemajuan Pertanian Indonesia. Penebar Swadaya. Bogor.

Sudjana. 2005. Teknik Analisis Regresi dan Korelasi. Tarsito. Bandung.

Sugiono. 2012. Metode Penelitian Pendidikan Pendekatan Kuantitatif, Kualitatif dan R \& D.

Alfabeta. Bandung. 
Susnto, Astrid S. 1978. Pengantar Sosiologi dan Perubahan Sosial, dalam Karsidi, Dari Petani Ke Pengrajin : Sebuah Studi Transformasi Pekerjaan. Pustaka Cakra Surakarta. Surakarta.

Tim BPP Kecamatan Kejuruan Muda. 2018. Monografi Badan Penyuluhan Pertanian Kecamatan Kejuruan Muda2018. BPP Kejuruan Muda. Aceh Tamiang.

Tim Penulis TPS 2012. Panduan Lengkap Karet. Penebar Swadaya. Jakarta.

Tim Penyusun . 2016. Statistik Perkebunan Aceh. Sekretariat Dinas Perkebunan Aceh. Banda Aceh.

Tim Penyusun Dinas Pertanian, Perkebunan dan Peternakan Kabupaten Aceh Tamiang. 2018. Produksi Karet Kabupaten Aceh Tamiang 2018. Sekretariat Dinas Pertanian, Perkebunan dan Peternakan Kabupaten Aceh Tamiang. Karang Baru. 